Article

\title{
Environmental Enrichment: Disentangling the Influence of Novelty, Social, and Physical Activity on Cerebral Amyloid Angiopathy in a Transgenic Mouse Model
}

\author{
Lisa S. Robison ${ }^{1,2} \oplus^{3}$, Nikita Francis ${ }^{1,3}$, Dominique L. Popescu ${ }^{1,4}{ }^{\oplus}$, Maria E. Anderson ${ }^{1,5}$, \\ Joshua Hatfield ${ }^{3,6}$, Feng $\mathrm{Xu}^{3,6}$, Brenda J. Anderson ${ }^{1}$, William E. Van Nostrand ${ }^{3,6}{ }^{1}$ and \\ John K. Robinson 1,3,6,7,* \\ 1 Department of Psychology, Stony Brook University, 100 Nicolls Road, Stony Brook, NY 11794, USA; \\ robisol@amc.edu (L.S.R.); nikita_francis@uri.edu (N.F.); dominique_popescu@brown.edu (D.L.P.); \\ mariaeanderson@gmail.com (M.E.A.); brenda.anderson@stonybrook.edu (B.J.A.) \\ 2 Department of Neuroscience and Experimental Therapeutics, Albany Medical College, 47 New Scotland Ave, \\ Albany, NY 12208, USA \\ 3 George \& Anne Ryan Institute for Neuroscience, 130 Flagg Road, University of Rhode Island, \\ Kingston, RI 02881, USA; jhatfield5210@gmail.com (J.H.); feng_xu@uri.edu (F.X.); \\ wvannostrand@uri.edu (W.E.V.N.) \\ 4 Department of Psychiatry and Human Behavior, Warren Alpert Medical School of Brown University, \\ 700 Butler Drive, Providence, RI 02906, USA \\ 5 Department of Psychology, Farmingdale State College, 2350 Broadhollow Rd, Farmingdale, NY 11735, USA \\ 6 Department of Biomedical and Pharmaceutical Sciences, University of Rhode Island, \\ Kingston, RI 02881, USA \\ 7 Department of Psychology, University of Rhode Island, Kingston, RI 02881, USA \\ * Correspondence: johnkrobinson@uri.edu; Tel.: +1-(401)-874-5651
}

Received: 2 January 2020; Accepted: 26 January 2020; Published: 28 January 2020

check for updates

\begin{abstract}
Cerebral amyloid angiopathy (CAA) is the deposition of amyloid protein in the cerebral vasculature, a common feature in both aging and Alzheimer's disease (AD). However, the effects of environmental factors, particularly cognitive stimulation, social stimulation, and physical activity, on CAA pathology are poorly understood. These factors, delivered in the form of the environmental enrichment (EE) paradigm in rodents, have been shown to have beneficial effects on the brain and behavior in healthy aging and AD models. However, the relative importance of these subcomponents on CAA pathology has not been investigated. Therefore, we assessed the effects of EE, social enrichment (SOC), and cognitive enrichment (COG) compared to a control group that was single housed without enrichment (SIN) from 4 to 8 months of age in wild-type mice (WT) and Tg-SwDI mice, a transgenic mouse model of CAA that exhibits cognitive/behavioral deficits. The results show that individual facets of enrichment can affect an animal model of CAA, though the SOC and combined EE conditions are generally the most effective at producing physiological, cognitive/behavioral, and neuropathological changes, adding to a growing literature supporting the benefits of lifestyle interventions.
\end{abstract}

Keywords: cerebral amyloid angiopathy; Alzheimer's disease; enriched environment; exercise; reserve; resilience

\section{Introduction}

Cerebral amyloid angiopathy (CAA), the deposition of amyloid protein in the cerebral vasculature, is common in the aging population and often co-exists with Alzheimer's disease (AD) [1]. CAA 
is associated with several other small vessel disease pathologies, including cerebral hemorrhages, white matter lesions, cortical microinfarcts, and perivascular inflammation [2-7]. There is a strong positive correlation between CAA and AD symptoms and pathology [8]. CAA is specifically linked to deficits in several cognitive domains, including perceptual slowing and episodic memory [9], and has been shown to be a better predictor of cognitive decline than parenchymal $\mathrm{A} \beta$ deposition in mouse models [10]. Unfortunately, there is currently no efficacious pharmaceutical intervention for CAA. Therefore, research to identify modifiable lifestyle factors that may reduce the risk and/or progression of dementia has come to the forefront. Epidemiological studies have identified a number of factors associated with a reduced risk of cognitive decline, including being physically active [11-14] and cognitive and social stimulation [11,15-18]. To help elucidate the causal relationship between these factors and outcomes, animal models can provide the opportunity to determine the contribution of these lifestyle factors to differential outcomes in pathology, cognitive performance, and additional related behaviors.

The complex interaction between physical-, social-, and cognitive-stimulating components can be modeled in rodents using the enriched environment (EE) paradigm. In the EE, rodents are usually group housed in a large cage with an exercise wheel, toys, and tunnels of varying shapes, colors, and sizes. The environment is altered several times per week by switching and moving around toys so that the rodents are always learning to navigate a novel environment. The effects of living in EE has been shown to result in enhanced neurogenesis, synaptogenesis, and angiogenesis [19-22], as well as increased dendritic arborization, growth factor levels [e.g., brain-derived neurotrophic factor (BDNF)], and cognition-linked gene expression [21,23-26]. These neural changes are accompanied by positive effects on behavior, including enhanced spatial and working memory $[21,27,28]$, as well as reduced anxiety- and depression-related behaviors [29-31]. The benefits of EE in healthy animals led to testing the effects of EE in several mouse models of AD pathology. Generally, studies have found that EE attenuates cognitive deficits; however, pathological findings have been mixed. Some studies have found that EE exposure results in cognitive benefits and reduced AD-related pathology [32,33] while another study showed benefits via amyloid-dependent and -independent mechanisms [34]. Other studies on EE found improved cognition in the absence of effects on pathology [35]. On the other hand, some studies have shown that EE improves cognitive performance while actually exacerbating amyloid pathology [36,37], perhaps by enhancing brain/cognitive reserve [38] or other mechanisms, such as reduced neuroinflammation.

While the full EE treatment, with its multiple components (novel objects, social stimulation, and physical activity), is a powerful manipulation, the contributions of each of the individual EE factors on AD pathology has been the subject of only limited study [39-43]. Further, no studies on EE have been performed on CAA. The present experiment used the Tg-SwDI mouse model of CAA to examine the contribution of these EE factors, alone and in combination, to differential outcomes in physiology, pathology, and behavior associated with this condition. From $4-8$ months of age, mice were single housed in standard conditions, single housed with cognitive enrichment, group housed (social enrichment), or housed in a standard enriched environment and tested for physiological, cognitive/behavioral, and neuropathological outcomes. We found that individual facets of enrichment can affect this model of CAA, though social housing and combined EE conditions are generally the most effective at producing changes in physiology, cognition/behavior, and neuropathology.

\section{Results}

Tg-SwDI mice are a transgenic mouse model of cerebral microvascular CAA type-1. Tg-SwDI mice begin to develop cerebral microvascular amyloid deposition starting at $\sim 3-4$ months of age. By 9 months of age, Tg-SwDI mice exhibit some CAA in the cortex, with more extensive deposition in the subiculum and thalamic regions (Figure 1). 

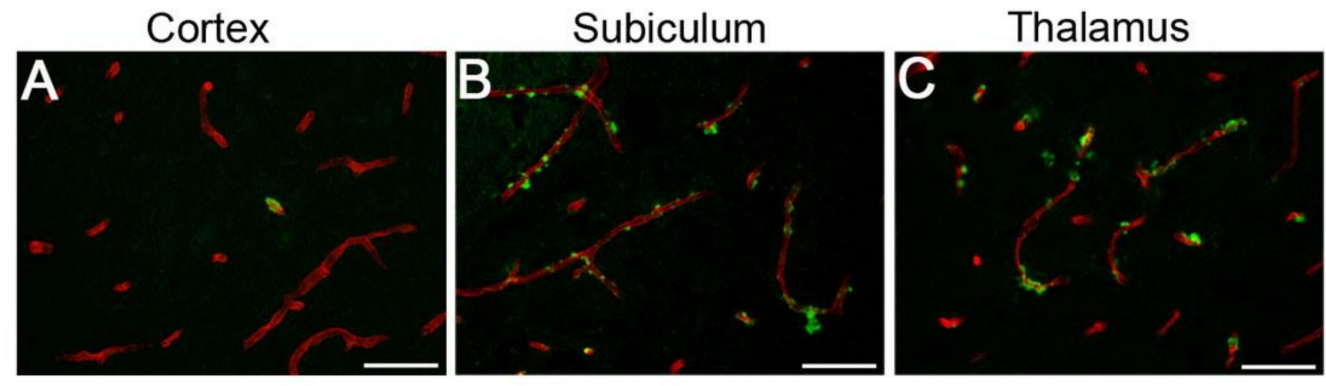

Figure 1. Cerebral microvascular amyloid accumulation in Tg-SwDI mice. Representative brain sections from 9-month-old Tg-SwDI mice stained with thioflavin S to identify fibrillar microvascular amyloid (green) and immunolabeled with an antibody to collagen IV to identify cerebral blood vessels (red). Microvascular amyloid deposits are observed in the cortex (A), subiculum (B), and thalamus (C). Scale bars $=50 \mu \mathrm{m}$.

A timeline of the experiment is shown in Figure 2. Briefly, wild-type (WT) and Tg-SwDI female mice were single-housed (SIN), single-housed with cognitive enrichment (COG), socially housed (SOC), or housed in a combined enriched environment condition consisting of cognitive, social, and physical (exercise wheel) enrichment (EE). Housing interventions started when mice were 3-4 months of age (when cerebral microvascular amyloid begins to appear) and lasted for 4 months (an age when microvascular amyloid is extensive; see Figure 1), after which several physiological, cognitive/behavioral, and neuropathological measures were assessed.
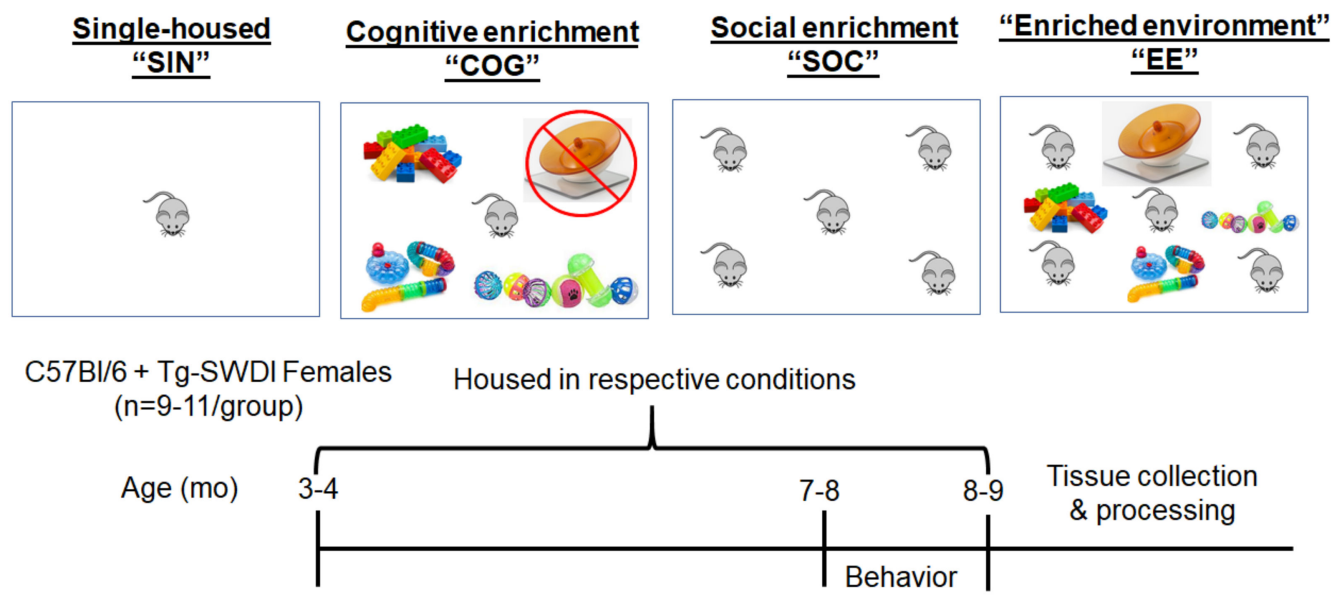

Figure 2. Overview of housing conditions and timeline of the experiment. At $\sim 3-4$ months of age, C57Bl/6 and Tg-SwDI female mice were randomly assigned to one of four housing conditions: SIN (single housed), COG (single housed with cognitively stimulating toys switched out twice weekly), SOC (group housed), and EE (group housed mice with toys and running wheel). Following 4 months in the respective housing conditions, mice underwent a battery of behavior tests, and tissue was collected (end age $=\sim 8-9$ months). Within housing conditions, access to a running wheel is indicated by the presence of an orange exercise saucer. Cognitive enrichment is indicated by the presence of multi-colored blocks, balls, and tunnels.

\subsection{Physiological Measures}

\subsubsection{Food Intake and Body Weight}

To assess if the different housing conditions affected the average daily food intake and body weight, these measurements were performed at the end of the experiment and are shown in Figure 3A,B, respectively. Tg-SwDI mice weighed less (main effect of genotype, $p<0.001$ ) despite eating slightly, 
but significantly, more compared to WT mice (main effect of genotype, $p<0.001$ ). These trends were apparent, but not always statistically significant, across housing conditions. There was also a main effect of housing condition $(p<0.001)$, such that SIN and COG mice ate similar amounts and more than SOC and EE groups, while EE mice also ate more than SOC mice $(p<0.01$ for all).

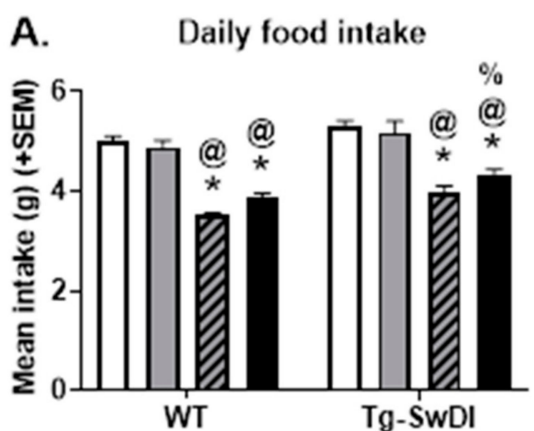

C.

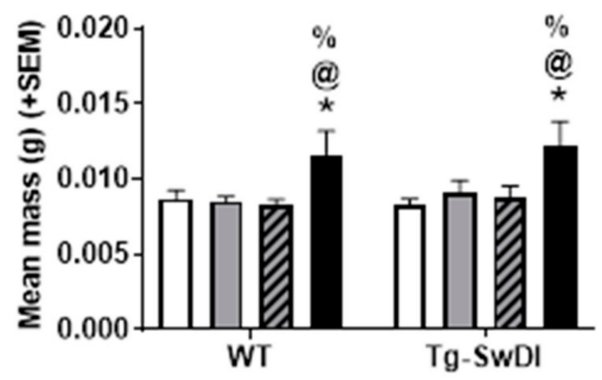

B. End body mass

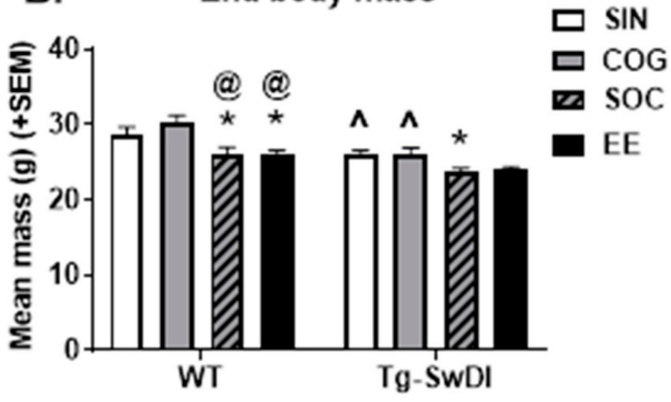

D. Gastrocnemius

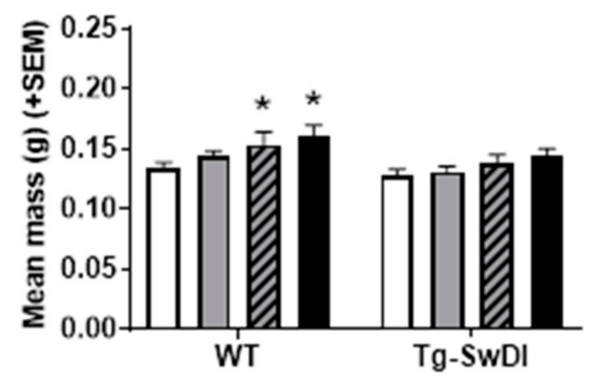

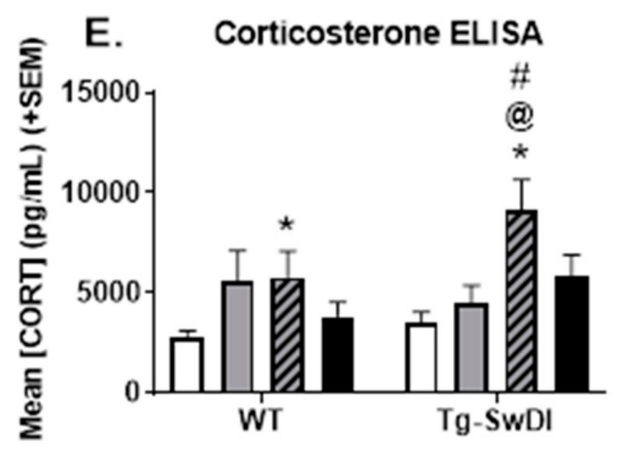

Figure 3. Physiological measures. (A) Mean daily food intake over the course of the 4-month intervention period. Generally, Tg-SwDI mice ate more than WT mice, while SOC and EE housing attenuated food intake in WT and Tg-SwDI mice. (B) Body weight at the end of the experiment. Generally, the Tg-SwDI mice weighed less than the WT mice. SOC (both WT and Tg-SwDI), and EE (WT only) reduced body weight. (C) Soleus mass was increased by EE housing in both WT and Tg-SwDI mice. (D) Overall, Tg-SwDI mice tended to have a smaller gastrocnemius. There were trends of SOC and EE mice of both genotypes having a larger gastrocnemius, but this was only significant in WT mice. (E) Corticosterone levels measured by ELISA. * $p<0.05$ vs. SIN of the same genotype, $@ p<$ 0.05 vs. COG of the same genotype, $\% p<0.05$ vs. SOC of the same genotype, \# $p<0.05$ vs. EE of the same genotype, ${ }^{\wedge} p<0.05$ vs. WT in the same housing condition.

\subsubsection{Muscle Mass}

To determine the effect of the housing conditions on muscle mass, the soleus (Figure 3C) and gastrocnemius (Figure 3D) muscles were dissected out and weighed upon euthanasia. There was no 
difference in the soleus mass between the two genotypes. There was a main effect of housing condition $(p<0.001)$, with EE having a larger soleus compared to all other groups $(p<0.001$ for all), and this was consistent across both genotypes ( $p<0.05$ for all). These trends of EE mice having an increased muscle mass were also observed when normalized to the body weight $(p<0.01$ for all).

There was a main effect of genotype $(p=0.009)$, such that Tg-SwDI mice had a smaller gastrocnemius muscle compared to WT mice, though pairwise comparisons within each housing condition did not reach significance. There was also a main effect of housing $(p=0.009)$, with EE mice having a larger gastrocnemius than SIN and COG mice, and SOC mice having a larger gastrocnemius than SIN mice ( $p<0.05$ for all). These trends were consistent but not always significant within individual genotypes. In WT mice, SOC and EE had a larger gastrocnemius than SIN mice ( $p<0.05$ for both), while in T-SwDI mice, the difference between EE and SIN mice only approached significance $(p=0.066)$. When muscle mass was normalized to body weight, both EE- and SOC-housed mice had a larger gastrocnemius compared to the SIN and COG groups ( $p<0.01$ for all except Tg-SwDI SOC vs. COG $p=0.089$ ). These findings indicate that the EE group had a higher muscle mass, regardless of genotype, likely attributed to the exposure to the running wheel and increased exercise.

\subsubsection{Corticosterone ELISA}

To assess the effect of the housing condition on stress levels in the mice, serum was collected at the time of euthanasia and corticosterone levels were measured by ELISA (Figure 3E). Neither the main effect of genotype, nor the genotype $x$ housing interaction, were significant for serum corticosterone levels. The main effect of housing was significant $(p=0.0012)$, such that enrichment conditions tended to increase corticosterone levels though this did not always reach significance (COG $p=0.0748$, SOC $p<0.0001$, EE $p=0.1146)$. Within WT mice, COG $(p=0.0575)$ and SOC $(p=0.0432)$ housing increased corticosterone levels compared to SIN mice. Within Tg-SwDI mice, SOC mice had higher corticosterone levels compared to all other housing conditions ( $p<0.05$ for all).

\subsection{Behavioral Tasks of Motor Function and Temperament}

\subsubsection{Rotarod}

Rotarod was performed to assess motor coordination and balance (Figure 4A). In SIN conditions, Tg-SwDI mice were impaired on the rotarod compared to WT mice $(p=0.028)$. However, in all other housing conditions, both genotypes performed similarly. There was an overall main effect of housing $(p<0.001)$, with EE mice performing better than mice in all other housing conditions $(p<0.001$ for all); these trends were significant within both WT and Tg-SwDI mice ( $p<0.05$ for all). In Tg-SwDI mice, there were also trends of COG $(p=0.050)$ and SOC $(p=0.085)$ conditions improving performance.

\subsubsection{Wire Hang}

Wire hang was performed to assess forelimb strength (Figure 4B). Tg-SwDI mice did not perform differently from WT mice under any housing conditions. There was an overall main effect of housing $(p=0.041)$, with EE mice performing better than mice housed in SIN conditions ( $p=0.005)$; however, pairwise comparisons revealed that this was significant in WT mice only $(p=0.012)$. 

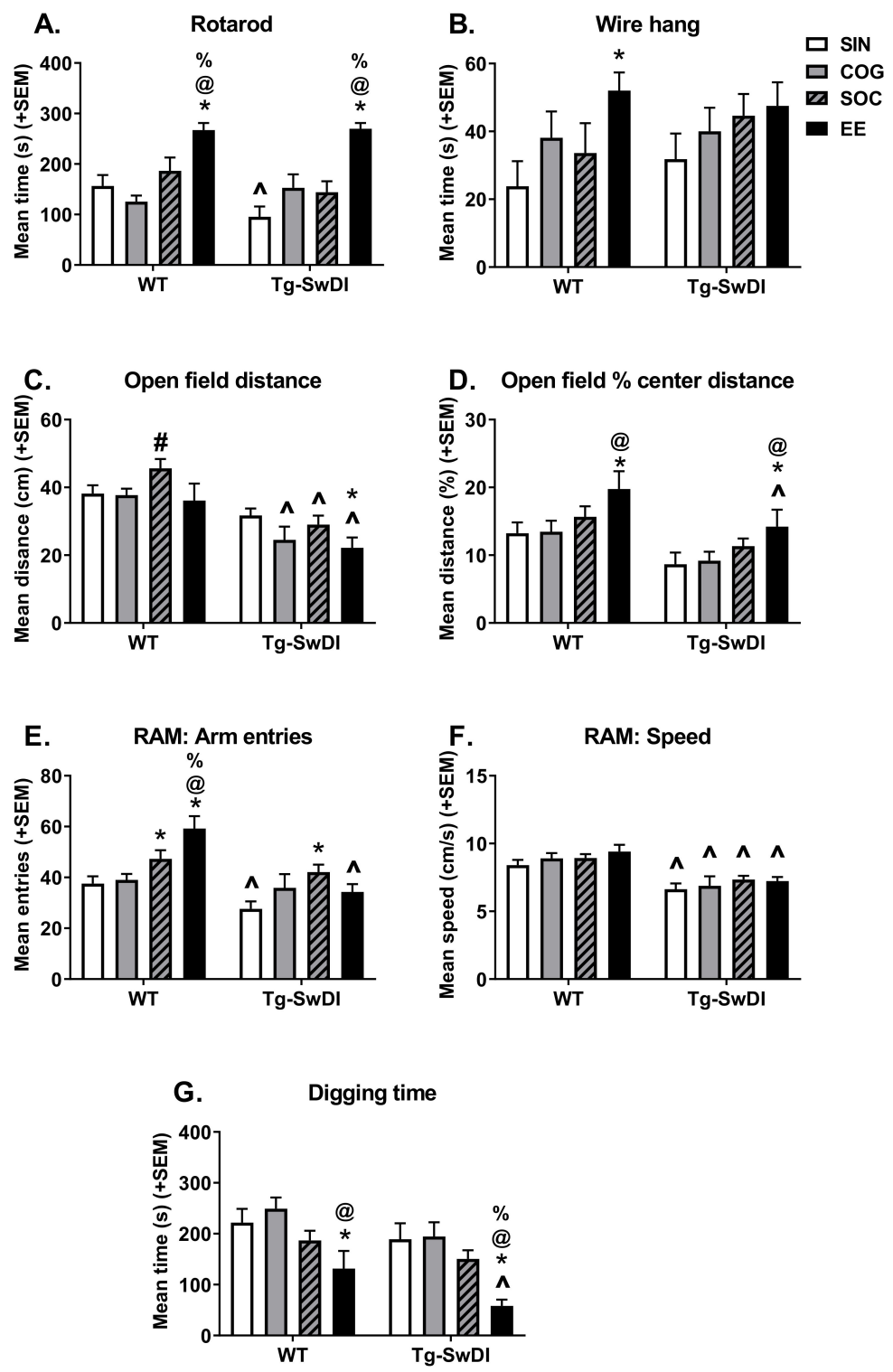

Figure 4. Activity and temperament measures. (A) Rotarod performance measured by time spent on rod (average of best two of three trials), indicative of balance and motor coordination. Under SIN conditions, Tg-SwDI mice were impaired in this task, while EE housing improved performance in both WT and Tg-SwDI mice. (B) Wire hang performance measured by time spent hanging onto a wire, indicative of forelimb strength. EE housing improved performance, but this was only significant in WT mice. (C) General activity levels, as measured by the distance traveled in the open field. SOC housing increased activity in WT mice. Overall, Tg-SwDI mice were hypoactive and this was exacerbated in EE mice. (D) Anxiety-like behavior, as measured by the percent of distance traveled in the center of the open field arena. Overall, Tg-SwDI mice exhibited increased anxiety-like behavior (less center activity), while anxiety was reduced by EE housing in both WT and Tg-SwDI mice. E and F) Exploratory behavior, as measured by the number of arm entries (E) and speed of travel (F) in the radial arm maze task. Generally, Tg-SwDI mice exhibited lower levels of exploration, and the number of arm entries was increased in SOC mice. In WT mice, SOC and EE housing increased the number of arm entries as well. (G) Time spent digging in a marble-burying task. Generally, Tg-SwDI mice exhibited lower levels of digging behavior, while EE housing attenuated digging behavior in both WT and Tg-SwDI mice. ${ }^{*} p<$ 0.05 vs. SIN of the same genotype, @ $p<0.05$ vs. COG of the same genotype, $\% p<0.05 \mathrm{vs.} \mathrm{SOC} \mathrm{of} \mathrm{the}$ same genotype, $\# p<0.05$ vs. EE of the same genotype, ${ }^{\wedge} p<0.05$ vs. WT in the same housing condition. 


\subsubsection{Open Field}

Open field was performed to assess general activity levels (distance traveled; Figure 4C) and anxiety-like behavior (center activity; Figure 4D). There was a main effect of genotype $(p<0.001)$, such that Tg-SwDI mice were less active in the open field compared to WT mice. This trend was consistent in all housing conditions $(p<0.05$ for all but $\operatorname{SIN} p=0.10)$. The main effect of housing was also significant $(p=0.036)$, though trends were not consistent across genotypes. In WT, SOC mice were more active than mice in all other housing conditions (SIN $p=0.074, \operatorname{COG} p=0.061$, EE $p=0.033$ ). In Tg-SwDI, enriched housing conditions did not rescue activity deficits; in fact, Tg-SwDI EE mice were less active than mice housed in the SIN condition $(p=0.023)$.

There was a main effect of genotype $(p<0.001)$, such that Tg-SwDI mice exhibited less center activity compared to WT mice. This trend was consistent in all housing conditions, though did not always reach statistical significance (SIN $p=0.065, \operatorname{COG} p=0.095$, SOC $p=0.086$, EE $p=0.042$ ). There was also a significant main effect of housing $(p=0.005)$, such that EE mice exhibited greater center activity compared to all other housing conditions $(p<0.05$ for all but SOC $p=0.067)$. When analyzed within individual genotypes, in both WT and Tg-SwDI mice, EE housing increased center activity compared to SIN and COG mice $(p<0.05$ for all) but not SOC mice.

\subsubsection{Unreinforced Radial Arm Maze}

The unreinforced radial arm was performed to assess exploratory behavior in a relatively complex environment by measuring the number of arm entries (Figure $4 \mathrm{E}$ ) and speed (Figure $4 \mathrm{~F}$ ). There was a main effect of genotype for the radial arm maze (RAM) entries $(p=0.0151)$, with Tg-SwDI mice making fewer arm entries compared to WT mice. When analyzed within housing conditions, this was significant for SIN $(p=0.0365)$ and EE $(p<0.0001)$ mice. The main effect of housing was also significant $(p=0.0003)$, such that SOC and EE mice made a greater number of arm entries compared to SIN and COG mice $(p<0.05$ for all). The genotype $\mathrm{x}$ housing interaction was also significant $(p=0.0151)$. In WT mice, there was an apparent stepwise effect of enrichment (EE $>$ SOC $>$ COG $=$ SIN; $p<0.05$ for all except SOC vs. COG $p=0.0931$ ). Within Tg-SwDI mice, only the SOC condition significantly increased arm entries compared to SIN mice $(p=0.0034)$.

There was a main effect of genotype for speed in the radial arm maze $(p<0.0001)$, with Tg-SwDI mice moving more slowly than WT mice, and this trend was consistent across housing conditions. The main effect of housing and the genotype $x$ housing interactions were not significant.

\subsubsection{Digging}

A marble-burying task was used to assess digging, a species-typical behavior (Figure 4G). There was a main effect of genotype $(p=0.008)$, such that Tg-SwDI mice exhibited less digging compared to WT mice; however, within the individual housing conditions, this only reached significance for EE mice $(p=0.027)$. There was also a significant main effect of housing $(p<0.001)$, with SOC and EE mice digging less than SIN and COG mice $(p<0.05$ for all except SIN vs. SOC $p=0.072)$. Additionally, EE mice dug less than SOC mice $(p=0.006)$. These trends were consistent across genotypes, though not all were statistically significant. In both WT and Tg-SwDI mice, EE mice dug less than SIN and COG mice ( $p<0.05$ for all). Only in Tg-SwDI mice did EE dig significantly less than SOC mice $(p=0.005)$.

\subsection{Cognitive Behavioral Performance}

\subsubsection{Novel Object Recognition}

A novel object recognition test was performed to assess non-spatial memory. The total time exploring both objects (Figure 5A) and the discrimination index for exploration of the novel object (Figure 5B) were measured. The main effect of housing condition $(p=0.013)$ and the genotype $\mathrm{x}$ housing interaction $(p=0.020)$ were significant. In the SIN condition, Tg-SwDI mice explored objects less than WT mice, though this only approached significance $(p=0.086)$, while this was reversed in the 
SOC condition (Tg-SwDI $>$ WT, $p=0.009)$. In WT mice, pairwise comparisons revealed no significant differences between groups; however, in Tg-SwDI mice, SOC and EE mice explored objects more than SIN and COG mice $(p<0.05$ for all).

A. NOR: Time with objects
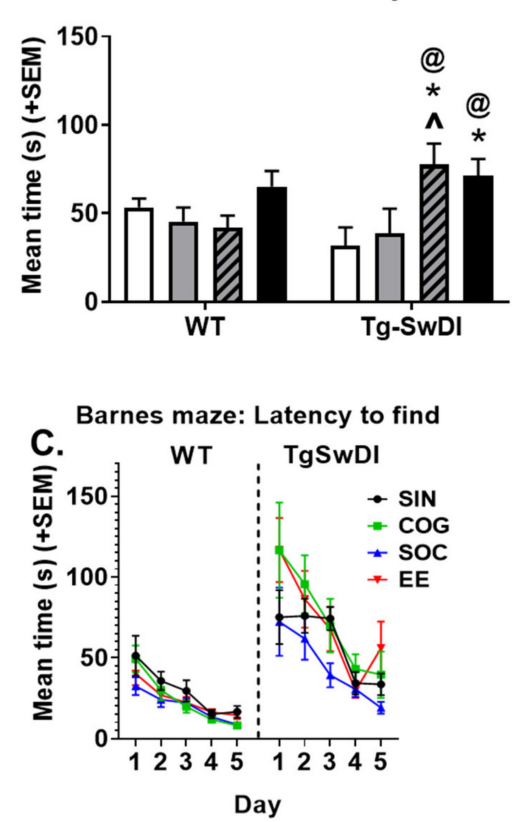

\section{B. NOR: Discrimination index}

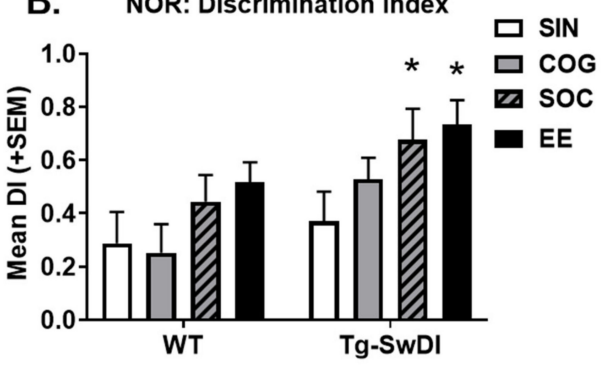

D. Barnes maze: Latency to find

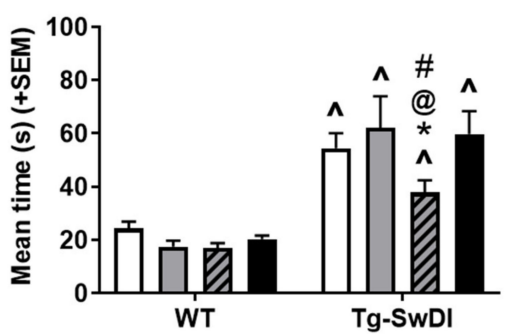

Figure 5. Cognitive testing. In Tg-SwDI mice, SOC and EE housing increased the amount of time spent with objects (A), and the discrimination index (B) in the novel object recognition (NOR) task. (C) Barnes maze performance, as measured by the latency to find the escape hole over time. (D) Barnes maze performance, as measured by the average latency to find the escape hole on days $2-5$. Tg-SwDI mice took longer to find the escape hole compared to WT mice in all housing conditions. In Tg-SwDI mice, SOC housing was associated with improved performance (shorter latency to find the escape hole). ${ }^{*} p<$ 0.05 vs. SIN of the same genotype, @ $p<0.05$ vs. COG of the same genotype, $\% p<0.05$ vs. SOC of the same genotype, $\# p<0.05 \mathrm{vs}$. EE of the same genotype, ${ }^{\wedge} p<0.05 \mathrm{vs}$. WT in the same housing condition.

The main effect of genotype was significant for the discrimination index in the novel object recognition (NOR) test, with Tg-SwDI mice outperforming WT mice $(p=0.009)$. Although pairwise comparisons revealed this was not statistically significant within any of the individual housing conditions, this genotype effect seemed to be driven more by enriched conditions and less so by the SIN condition in which discrimination indices were more comparable. Additionally, the main effect of housing was significant $(p=0.019)$, with EE and SOC groups displaying increased performance. In WT mice, pairwise comparisons revealed no statistically significant differences between groups; however, in Tg-SwDI mice, both SOC and EE groups outperformed SIN mice ( $p<0.05$ for both).

\subsubsection{Barnes Maze}

The Barnes maze task was run over a period of five days, with two trials per day. Spatial learning and memory were assessed by the measure of latency to find the escape hole over the course of the five days (Figure 5C) and the average latency to find on days 2-5 (Figure 5D). Negative slopes of latency to find over the course of the five days indicated that all groups were able to learn the task over time. There was a striking main effect of genotype $(p<0.001)$, with Tg-SwDI mice finding the escape box more slowly than WT mice, regardless of the housing condition. Within WT mice, enriched groups generally outperformed SIN mice, but these comparisons were not significant. Within Tg-SwDI mice, SOC mice found the escape hole more quickly than mice in all other housing conditions ( $p<0.05$ for all). 


\subsection{Pathology}

\subsubsection{ELISAs for $\mathrm{A} \beta$ Species}

ELISAs were performed on whole forebrain homogenates to assess the effect of the housing condition on the levels of $A \beta$ species (Figure 6A). There were no effects of the housing condition on soluble $A \beta$ species ( 40 or 42 ); however, thee housing condition did affect the forebrain levels of insoluble $\mathrm{A} \beta 40(p=0.010)$ and $\mathrm{A} \beta 42(p=0.064)$. Surprisingly, pairwise comparisons revealed that all enrichment conditions increased insoluble A $\beta 40$ levels compared to SIN mice $(p<0.05$ for all but SOC $p=0.053$ ). Similar trends were seen for insoluble A $\beta 42$; however, only EE housing led to a statistically significant increase $(p=0.009)$. Since WT mice do not accumulate microvascular amyloid, they were not included in these measures.
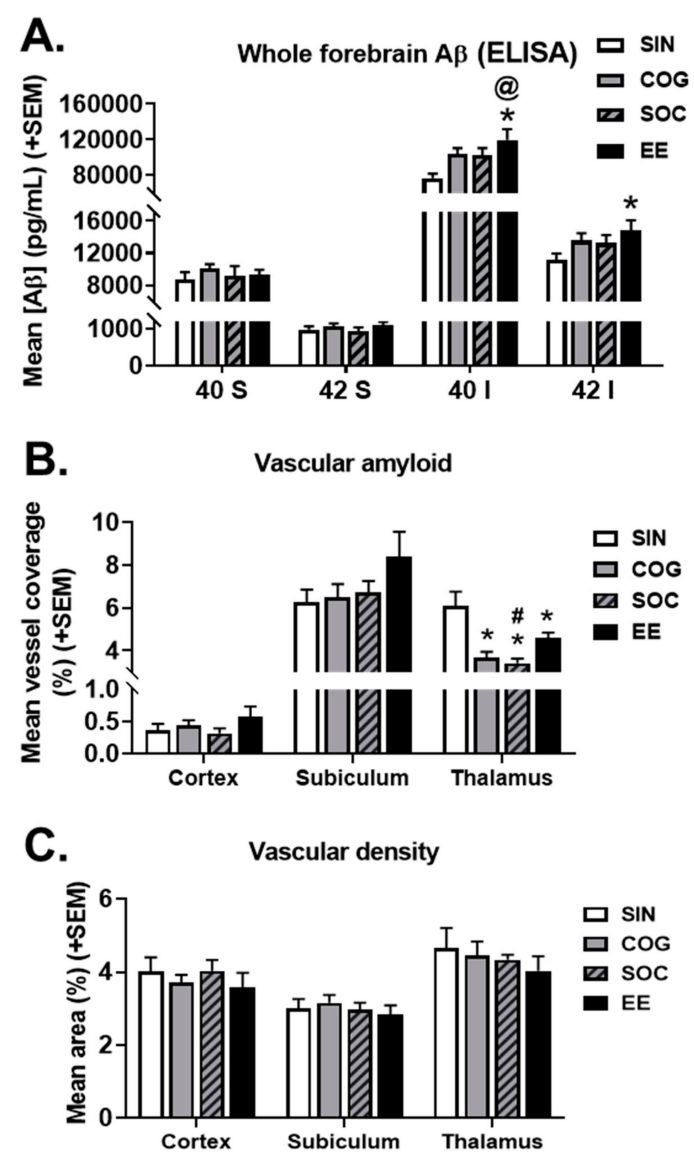

Figure 6. Effects of the housing condition on the accumulation of $A \beta$ in Tg-SwDI mice. (A) Tg-SwDI mice housed in EE conditions had increased insoluble $A \beta 40$ and $A \beta 42$ ) levels, as measured by ELISA of whole forebrain homogenates. (B) Tg-SwDI mice in all enrichment conditions had less vascular amyloid in the thalamus compared to single-housed mice. (C) The housing condition did not affect the cerebral vascular density in any of the three brain regions measured. ${ }^{*} p<0.05 \mathrm{vs}$. SIN of the same genotype, @ $p<0.05$ vs. COG of the same genotype, \# $p<0.05$ vs. EE of the same genotype.

\subsubsection{Microvascular Amyloid Deposition}

Since there were effects of the housing condition on the accumulation of insoluble $A \beta$, particularly insoluble $A \beta 40$, we measured the extent of microvascular amyloid deposition in different brain regions (Figure 6B). One-way ANOVAs found no effect of housing on microvascular amyloid deposition in the cortex or subiculum; however, there was a significant effect in the thalamus $(p<0.001)$, with all enrichment groups having reduced vascular amyloid compared to SIN mice ( $p<0.05$ for all). Additionally, SOC mice had less vascular amyloid compared to EE mice $(p=0.045)$. 


\subsubsection{Vascular Density}

Since the accumulation of insoluble A $\beta$ tended to increase, whereas the microvascular CAA load was either unchanged or in the case of the thalamus was reduced, we next determined if the EE conditions impacted the cerebral vascular density in Tg-SwDI mice. Cerebral vascular density, however, was not affected by housing condition in any of the regions measured (cortex, subiculum, and thalamus) (Figure 6C).

\section{Discussion}

Lifestyle factors, such as exercise and participating in cognitively and socially stimulating activities, promote healthy aging and prevent the risk of dementia in elderly populations [11-18]. These findings are supported by studies in healthy mice [19-31] and rodent models of AD [32-37], often combining these three factors in the enriched environment (EE) paradigm. Few studies have aimed to directly compare and tease apart the contribution of individual and combined EE factors in AD mouse models, and those that did utilized models that primarily develop parenchymal amyloid [39,40]. This study, for the first time, determined the protective effects of environmental enrichment (EE) in the Tg-SwDI mouse model of CAA, a condition characterized by the accumulation of cerebral vascular amyloid found to be common in aging and seen in the vast majority of AD cases [1]. We also disassembled the EE paradigm to determine the unique contributions of its cognitively and socially stimulating components.

Mice housed in the cognitively enriched condition (COG; single housed with toys and tunnels switched out $2 \times /$ week to provide novelty) exhibited few cognitive/behavioral benefits compared to single-housed mice without such added enrichment. Tg-SwDI mice housed in the COG condition did display improved performance on some tasks of motor function (rotarod) and exploratory behavior (radial arm maze), in addition to reduced cerebral microvascular amyloid pathology in the thalamus. Mood- and cognition-related behavior was unaffected by cognitive stimulation, in line with our previous findings in Tg-SwDI and 5xFAD mice. In these strains, we provided cognitive enrichment using a progressive cognitive stimulation paradigm meant to model commercialized brain training games in humans, which included 4 months of progressively difficult domain-specific operant tasks [44]. Results from this previous study supported clinical findings that while brain training games enhance performance on the specific task being trained, improvements do not generalize to other cognitive domains to improve global function, promote brain health, or prevent cognitive decline [45-48].

On the other hand, the current study provides evidence that socially housed mice, and those housed in a completely enriched environment, displayed the greatest changes in physiological and cognitive/behavioral outcomes. These mice, in general, exhibited a similarly reduced body weight and food intake, and improved performance on the novel object recognition task. As expected, the EE condition produced greater changes for some outcomes, such as muscle mass, tests of motor function and activity levels, and anxiety-like behavior, likely due to the addition of access to a running wheel to engage in voluntary aerobic exercise. Similarly, we previously reported the dose-dependent effects of aerobic exercise (voluntary wheel running) in WT mice and the Tg-SwDI model, with even relatively small amounts of exercise exerting notable benefits to physiology, motor function, anxiety, and cognition [49,50]. It should be noted that social and EE housing also reduced food intake and body weight in both WT and Tg-SwDI mice. Caloric restriction has been shown to improve memory and reduce dementia risk in humans, and increase cognitive function in animal models of healthy aging and $\mathrm{AD}$ [51-56]. These cognitive behavioral benefits are associated with decreased inflammation, oxidative stress, and AD pathology, and increased insulin sensitivity, autophagy, and neurogenesis [54,57-59]. In the current study, the reduced caloric intake displayed by SOC and EE mice of both genotypes fall approximately within the range of 20-40\% typically used in rodent studies (WT SOC: $-29 \%$, WT EE: $-23 \%$, Tg-SwDI SOC: $25 \%$, Tg-SwDI EE: $18 \%$ ). Additionally, caloric deficits were likely exacerbated by increased energy output, particularly in EE mice with access to a running wheel. The likelihood of increased physical activity and therefore caloric expenditure by these groups is supported by their 
increased muscle mass. Therefore, one possibility is that enriched housing conditions exert behavioral benefits indirectly by affecting caloric intake and/or metabolic outcomes.

Interestingly, though thalamic vascular amyloid was specifically reduced by all forms of enriched housing, the levels of insoluble $\mathrm{A} \beta$ as detected by ELISA were actually somewhat increased in Tg-SwDI mice housed in the EE condition. Although the nature of this increase is unclear, this is in agreement with early studies by Jankowsky et al. [36,37], which found that six months of housing in an enriched enrichment also increased A $\beta$ levels in APPswe and APPswe/PS1dE9, despite these mice showing enhanced performance in spatial memory tasks (Morris water maze and radial water maze) [36,37]. While there were trends of COG and SOC mice also having increased insoluble A $\beta$ in our study, these effects were not significant. Therefore, these types of enrichment stimulation appear to have additive incremental effects on insoluble $A \beta$ levels. As in previous studies, we found that these increased levels of insoluble $A \beta$ occurred in the presence of behavioral improvement and were therefore not detrimental to functioning, in agreement with previous findings that insoluble $A \beta$ exhibits low toxicity [60-62]. Previously, we showed that exercise alone was also capable of dose-dependently increasing insoluble A $\beta$ levels, despite some behavioral improvements and attenuated neuroinflammation [49]. Taken together, these findings suggest that enrichment factors increase the production/aggregation or reduce the degradation/clearance of $A \beta$, though vascular amyloid was specifically reduced in some brain regions. One possible explanation for the former is that enriched housing may increase neuronal activity, which could enhance $A \beta$ production and deposition $[63,64]$. The effects of environmental enrichment on $\mathrm{A} \beta$ production and clearance in Tg-SwDI mice should be further assessed. Moreover, enrichment could affect other measures rather than insoluble $A \beta$ to influence behavior and cognition, such as reducing neuroinflammation and increasing hippocampal growth factors and neurogenesis [65-67]. Investigation of these other possible mechanisms could not only offer an alternative explanation to $A \beta$ burden in Tg-SwDI animals but also explain enrichment effects within WT mice.

This study represents one of the first to disentangle the contributions of EE factors in a mouse model of CAA. In a previous study, APP-23 mice were housed in standard or enriched conditions, or in cages with access to a running wheel. Enriched mice had improved performance on the Morris water maze despite an unchanged amyloid burden, though they did exhibit increased levels of BDNF and hippocampal neurogenesis. In contrast, exercise had no effect on cognitive performance or neurogenesis; however, there was a decrease in growth factors in the cortex and hippocampus [39]. In another study, APPsw/APP + PS1 mice were grouped into environments that layered on these factors (impoverished, social, social + physical, complete enrichment) from 1.5-9 months of age. Only the completely enriched environment was capable of protecting against cognitive decline, reducing $\mathrm{A} \beta$ deposition, and increasing synaptic reactivity in the hippocampus, while no differences between groups in corticosterone or inflammatory cytokines were observed [40]. Recent clinical findings also provide evidence that adopting multiple healthy lifestyle factors exerts a benefit on the body and brain. The Finnish Geriatric Intervention Study to Prevent Cognitive Impairment and Disability (FINGER) study was a randomized controlled trial to assess a two-year multidomain intervention (diet, exercise, cognitive training, vascular risk monitoring), finding it effective at preventing cognitive decline in an at-risk elderly population [68]. Recently reported at the 2019 Alzheimer's Association International Conference (AAIC), a study using the data of over 2000 people from the Chicago Health and Aging Project and the Rush Memory and Aging Project determined that aging adults that exhibited four to five healthy lifestyle factors (diet, exercise, and cognitive stimulation, in addition to smoking and alcohol use) had the greatest reduction in risk for $\operatorname{AD~}(\sim 60 \%)$. Additionally, regardless of the number of current healthy lifestyle factors exhibited, adopting just one more reduced the risk by $22 \%$ [69]. Other data presented at the 2019 AAIC suggest that a healthy lifestyle can even counteract genetic risk for dementia, boasting a 32\% reduction [70]. Our findings, for the first time, show that EE can be beneficial by specifically targeting CAA, and add to a growing literature supporting that the adoption of a healthy lifestyle is key to healthy aging, and specifically brain health, and for reducing the risk of cognitive decline and dementia in later life. 


\section{Materials and Methods}

\subsection{Animals}

Female C57BL/6 (wild type; WT) and Tg-SwDI mice were used in this experiment. The Tg-SwDI mouse is a model of CAA, in which fibrillar $\mathrm{A} \beta$ accumulates primarily in the cerebral microvasculature, apparently, in part, due to insufficient clearance of the protein across the blood-brain barrier [71]. These mice are on a C57BL/6 background and express low levels of the human amyloid precursor protein (APP) gene, containing the Swedish K670N/M671L, Dutch E693Q and Iowa D694N mutations, under the control of the mouse Thy1 promoter [72]. CAA pathology is accompanied by vascular degeneration and marked gliosis [73], as well as impaired Barnes maze performance not attributable to deficits in mobility, strength, or coordination [74].

Mice were housed in a controlled room $\left(22 \pm 2{ }^{\circ} \mathrm{C}\right.$ and $40-60 \%$ humidity) with a $12-\mathrm{h}$ reverse light-dark cycle (lights off $0800 \mathrm{~h}$ ). Mice were habituated for one week prior to the beginning of the experiment, and then split into experimental treatment groups at 3-4 months of age. Purina Lab Diet rat chow was available ad libitum, and body weight and food intake were recorded weekly throughout the entire experiment. All experiments were conducted in conformity with the National Academy of Sciences Guide for Care and Use of Laboratory Animals and approved by the Stony Brook University Institutional Animal Care and Use Committee. (Project identification code: 2013-0788; date: 17 November 2014)

\subsection{Housing Conditions}

Mice of each genotype were split into experimental housing conditions: WT single-housed (WT SIN; $n=11$ ), WT cognitively enriched (WT COG; $n=10$ ), WT socially enriched (WT SOC; $n=10)$, WT fully enriched (WT EE; $n=8)$, Tg-SwDI SIN $(n=11)$, Tg-SwDI COG $(n=9)$, Tg-SwDI SOC $(n=10)$, and Tg-SwDI EE $(n=10)$. SIN mice were housed one per cage. COG mice were housed one per cage, with toys (colored blocks, balls, and tunnels) that were changed out twice weekly. SOC mice were group housed (4-6 mice/cage). EE mice were group housed (4-6 mice/cage) in a cage equipped with an exercise wheel and toys (colored blocks, balls, and tunnels) that were changed out twice weekly. Mice remained in these housing conditions for the duration of the experiment. An illustration of housing conditions and timeline of the experiment can be seen in Figure 1.

\subsection{Cognitive/Behavioral Assessments}

Following four months of housing in the respective conditions, all mice underwent a battery of behavioral testing, including the rotarod, wire hang, open field, unreinforced radial arm maze, marble burying, novel object recognition, and Barnes maze. Mice remained in their housing conditions throughout the duration of testing. All behavior testing, except for rotarod, was recorded and analyzed using ANY-maze tracking software.

\subsubsection{Rotarod}

Rotarod was performed to assess balance, strength, and motor coordination. The apparatus (model ENV-575M; MED Associates Inc.) is composed of a 30-cm-long rod that is divided into five equally sized 6-cm sections. The mice were placed on the rotarod, which spun at an increasing speed of up to 40 revolutions per minute over a five-minute period. The time on the rod until the mouse fell (maximum time of five minutes) was recorded. The mice were tested three times, with a minimum five-minute inter-trial interval, and the average of the last two trials was used for the analysis.

\subsubsection{Wire Hang}

The wire hang consisted of a single trial to assess muscle strength/endurance using an apparatus consisting of a 43-cm-long wire stretched between two wooden poles, $48 \mathrm{~cm}$ high above the base. Foam 
padding was placed on the platform to cushion a fall. At the beginning of the trial, the mouse's two front paws were placed on the wire and the mouse was allowed to hang until it fell or for a maximum of one minute. The latency to fall was recorded (maximum one minute).

\subsubsection{Open Field}

The mice were placed in a square $60 \mathrm{~cm} \times 60 \mathrm{~cm}$ open field arena for $10 \mathrm{~min}$. Behavior was recorded using ANY-maze software. General locomotor behavior and motor function was assessed using the measure of the distance traveled in the open field. Since mice are agoraphobic, anxiety-like behavior was assessed by the time spent in the center of the open field [75]. Measures of general activity and agoraphobia-related anxiety are also useful in the interpretation of any differences in performance observed in other cognitive/behavioral tasks.

\subsubsection{Unreinforced Radial Arm Maze}

The mice were placed in a radial arm maze with eight arms for five minutes. The number of arm entries was assessed as a measure of exploratory behavior in a novel and relatively complex environment (compared to the open field).

\subsubsection{Marble Burying}

The protocol for marble burying was adapted from a well-defined protocol [76]. The mice were place in a rat-sized tub cage filled with $5 \mathrm{~cm}$ of corn cob bedding for five minutes with 20 marbles in a 5 $\mathrm{x} 4$ array, during which time the time spent digging was recorded. Digging was defined as coordinated movements of the fore or hind limbs that displaced the bedding.

\subsubsection{Novel Object Recognition}

A novel object recognition task was performed to assess non-spatial learning and memory (Figure 5). This task consisted of two trials, each lasting $5 \mathrm{~min}$, with an inter-trial interval of $15 \mathrm{~min}$. In the first trial, two of the same objects were placed in the open field arena. In the second trial, one object was replaced by a novel object, while the other object remained the same and in the same location. The time spent exploring both objects was counted, and novel object recognition was assessed by calculating the discrimination index (DI). DI = (time with novel object-time with familiar object)/(time with novel object—-time with familiar object).

\subsubsection{Barnes Circular Maze}

The Barnes maze was originally developed to test learning and memory in rats. We used an adaptation of this maze, a circular wooden platform, $91 \mathrm{~cm}$ in diameter, elevated $75 \mathrm{~cm}$ off the ground. The platform has eight equally spaced escape holes along the periphery that are $24.5 \mathrm{~cm}$ apart. Under each hole, a shelf securely held an escape box, measuring $10 \mathrm{~cm} \times 8.5 \mathrm{~cm} \times 4 \mathrm{~cm}$. There were visible distal cues placed around the room, which remained constant throughout the duration of testing. Testing were performed on five consecutive days, with two trials per day separated by a 15-min inter-trial interval. Mice were placed onto the center of the maze at the beginning of each trial, then allowed to explore until the escape box was found and entered, or a maximum of five minutes. If the escape box was entered, the mouse remained there for one minute before being transferred back to its home cage. If the escape box was not entered within five minutes, the mouse was placed in the escape box and left there for one minute. During each trial, the following measures were recorded: Latency to find (amount of time taken to find the escape box), latency to enter (amount of time taken to enter the escape box), and errors (number of nose pokes into a hole that did not contain the escape box before finding the escape box). 


\subsection{Physiological Measures}

\subsubsection{Blood, Organ, and Muscle Collection}

Following the completion of behavioral testing, mice were euthanized under deep anesthesia with $2.5 \%$ avertin. Cardiac puncture was performed to collect blood, which was allowed to clot at room temperature for $30 \mathrm{~min}$, spun at $2000 \times \mathrm{g}$ for $10 \mathrm{~min}$, and serum was collected and stored at -80 ${ }^{\circ} \mathrm{C}$ until use in the assays. Following blood collection, mice were perfused with saline. Muscles were collected to assess exercise-induced differences in muscle mass. After weighing, brains were bisected along the midline and prepared for subsequent pathological analyses. One hemisphere was placed in $70 \%$ ethanol and subsequently paraffin embedded for immunohistochemistry, while the other was flash frozen in liquid nitrogen for ELISAs and quantitative polymerase chain reaction.

\subsubsection{Enzyme Linked Immunosorbent Assay (ELISA) For Serum Corticosterone}

Serum samples were analyzed using a commercially available ELISA for corticosterone according to the manufacturer's instructions (Cayman Chemical). Absorbance was recorded using a plate reader (Spectramax).

\subsection{Pathological $A \beta$ Measures}

\subsubsection{Enzyme-Linked Immunosorbent Assay (ELISA) For A $\beta$ Species}

ELISAs were performed to quantify whole brain levels of membrane, soluble, and insoluble forms of $A \beta 40$ and $A \beta 42$. Brain hemispheres that were flash frozen were pulverized and separated into three aliquots. A soluble fraction was obtained by homogenized tissue with $10 \mu \mathrm{L} / \mathrm{mg}$ TBS using $0.5 \mathrm{~mm}$ glass beads and a bullet blender. Aliquots were centrifuged at $1600 \times \mathrm{g}$ at $4{ }^{\circ} \mathrm{C}$ for $20 \mathrm{~min}$. The supernatant was removed, which was the soluble fraction. The remaining pellet was resuspended in $5 \mathrm{M}$ guanidine- $\mathrm{HCl}$ at $\mathrm{pH}$ 8.0, and rotated at room temperature for $3 \mathrm{~h}$. Samples were centrifuged as above, and the supernatant was removed, which was the insoluble fraction. For each fraction, a sandwich ELISA for $A \beta$ was performed using antibody reagents generously provided by Eli Lilly (Indianapolis, IN). Well plates were coated with $1 \mu \mathrm{L} /$ well of A $\beta 40$-specific antibody M2G3 or A $\beta 42$-specific antibody M21F12. Plates were blocked and shaken overnight at $4{ }^{\circ} \mathrm{C}$. A $\beta$ species were detected using biotinylated-m3DG, followed by streptavidin-HRP (Amdex RPN4401V). Plates were developed using SureBlue (KPL) and plates were read with a plate reader (Spectramax).

\subsubsection{Immunostaining and Analysis}

Immunohistochemical analyses were performed as described in $\mathrm{Xu}$ et al. (2007) on Tg-SwDI brain tissue ( $n=6-7 /$ group). Brain hemispheres embedded in paraffin were sectioned at a $10-\mu \mathrm{M}$ thickness and mounted on glass slides. Paraffin was removed from sections by immersion in xylene $(3 \times 5 \mathrm{~min})$ and rehydrated in decreasing concentrations of ethanol $(100 \%, 95 \%, 70 \%, 50 \%, 0 \%$ at 5 min each). Slides were dipped in PBS for $5 \mathrm{~min}$, followed by a 5 min incubation with proteinase $\mathrm{K}$ (1:1000 in PBS) for antigen retrieval, then dipped in distilled water 5x 1min. Buffer consisting of $0.3 \%$ Triton X-100 was used to block sections for $30 \mathrm{~min}$, which were then incubated with primary antibody (1:100 collagen type IV for blood vessels) in a 1:10 0.1\% Triton X-100 blocking buffer solution overnight at room temperature. The next day, slides were washed $3 \times 5 \mathrm{~min}$ with distilled water, then incubated for $2 \mathrm{~h}$ with secondary antibody (1:1000 594 anti-Rabbit) in a 1:10 0.1\% Triton X-100 blocking buffer solution. Slides were rinsed with distilled water. Slides were then stained for Thioflavin-S $(0.0125 \%$ Thioflavin-S in 50\% EtOH/PBS) by incubating for $15 \mathrm{~min}$ at room temperature. Slides were rinsed $3 \times$ with distilled water then $2 \times$ with $70 \% \mathrm{EtOH}$ and then washed for $5 \mathrm{~min}$ in distilled water. Anti-fade reagent in glycerol/PBS was added to each slide and coverslipped, then sealed with mounting media. Sections were imaged using an Olympus BX60 microscope with an attached Olympus Dp72 camera. Images from the cortex, subiculum, and thalamus were collected from each section at the 
$40 \times$ magnification. Using NIH ImageJ software, an appropriate threshold was set for each stain and the percent area occupied with positive stain was quantified. Fibrillar vascular amyloid deposition were assessed in the cortex, subiculum, and thalamus. These regions were chosen as they have been previously shown to accumulate cerebral microvascular amyloid and are involved in several of the behavioral tasks used in the current study. Fibrillar amyloid deposition was calculated by measuring the percentage of positive staining for thioflavin-S. Vascular amyloid deposition (percentage of blood vessel coverage with fibrillar amyloid) was calculated by [(ThioflavinS+ stain/Collagen IV+ stain) * 100]. Fibrillar vascular amyloid was only assessed in Tg-SwDI mice, as WT mice do not show any accumulation in brain. Additionally, the effects of exercise on the vascular density were assessed as the area of labeling for collagen IV in the cortex, subiculum, and thalamus.

\subsection{Statistical Analyses}

Two-way ANOVAs (factors: Genotype and housing) were performed to determine differences between groups for organ and muscle mass, serum corticosterone concentration, and behavioral and pathological measures. Three-way repeated measures ANOVAs were performed to assess differences in groups over time for food intake and body weight, as well as group differences in Barnes maze performance measures over time. Analyses were performed using Statistica and SigmaPlot/Stat, and significance was set at alpha $=0.05$.

Author Contributions: Conceptualization, L.S.R., J.K.R., W.E.V.N., B.J.A.; methodology, L.S.R., J.K.R., W.E.V.N.; formal analysis, L.S.R.; investigation, L.S.R., N.F., D.L.P., M.E.A., J.H., F.X.; resources, J.K.R, W.E.V.N.; writing — original draft preparation, L.S.R. and J.K.R.; writing—review and editing, all authors; visualization, L.S.R.; supervision and project administration, L.S.R., D.L.P., J.K.R, W.E.V.N.; funding acquisition, J.K.R, W.E.V.N., B.J.A. All authors have read and agreed to the published version of the manuscript.

Funding: This work was supported by NIH grant AG048935.

Acknowledgments: The authors would like to thank Shannon Fitzgerald, Antonina Kuzmina, David Lituma, Sarima Subzwari, Michael Michaelos, Sarah Amrein, Wendi Liu, Regina Kim, Rachel Rock, Joseph Sullivan, and Judianne Davis for their technical assistance. Antibody reagents for the A $\beta$ ELISAs were generously provided by Eli Lilly, Indianapolis, IA.

Conflicts of Interest: The authors declare no conflict of interest.

$\begin{array}{ll}\text { Abbreviations } \\ \text { A } \beta & \text { Beta amyloid } \\ \text { AD } & \text { Alzheimer's disease } \\ \text { APP } & \text { Amyloid precursor protein } \\ \text { BDNF } & \text { Brain-derived neurotrophic factor } \\ \text { CAA } & \text { Cerebral amyloid angiopathy } \\ \text { COG } & \text { Cognitively enriched treatment group } \\ \text { DI } & \text { Discrimination index } \\ \text { EE } & \text { Enriched environment } \\ \text { ELISA } & \text { Enzyme-linked immunosorbent assay } \\ \text { NOR } & \text { Novel object recognition } \\ \text { PBS } & \text { Phosphate buffered saline } \\ \text { SIN } & \text { Single-housed treatment group } \\ \text { SOC } & \text { Socially (group)-housed treatment group } \\ \text { TBS } & \text { Tris Buffered Saline } \\ \text { WT } & \text { Wild-type mice }\end{array}$




\section{References}

1. Yamada, M. Risk factors for cerebral amyloid angiopathy in the elderly. Ann. New York Acad. Sci. 2002, 977, 37-44. [CrossRef]

2. Kinnecom, C.; Lev, M.; Wendell, L.; Smith, E.; Rosand, J.; Frosch, M.; Greenberg, S. Course of cerebral amyloid angiopathy-related inflammation. Neurology 2007, 68, 1411-1416. [CrossRef] [PubMed]

3. Suter, O.-C.; Sunthorn, T.; Kraftsik, R.; Straubel, J.; Darekar, P.; Khalili, K.; Miklossy, J. Cerebral hypoperfusion generates cortical watershed microinfarcts in Alzheimer disease. Stroke 2002, 33, 1986-1992. [CrossRef] [PubMed]

4. Holland, C.M.; Smith, E.E.; Csapo, I.; Gurol, M.E.; Brylka, D.A.; Killiany, R.J.; Blacker, D.; Albert, M.S.; Guttmann, C.R.; Greenberg, S.M. Spatial distribution of white-matter hyperintensities in Alzheimer disease, cerebral amyloid angiopathy, and healthy aging. Stroke 2008, 39, 1127-1133. [CrossRef]

5. Yoshita, M.; Fletcher, E.; Harvey, D.; Ortega, M.; Martinez, O.; Mungas, D.; Reed, B.; DeCarli, C. Extent and distribution of white matter hyperintensities in normal aging, MCI, and AD. Neurology 2006, 67, 2192-2198. [CrossRef] [PubMed]

6. Viswanathan, A.; Patel, P.; Rahman, R.; Nandigam, R.K.; Kinnecom, C.; Bracoud, L.; Rosand, J.; Chabriat, H.; Greenberg, S.M.; Smith, E.E. Tissue microstructural changes are independently associated with cognitive impairment in cerebral amyloid angiopathy. Stroke 2008, 39, 1988-1992. [CrossRef] [PubMed]

7. Attems, J.; Lauda, F.; Jellinger, K.A. Unexpectedly low prevalence of intracerebral hemorrhages in sporadic cerebral amyloid angiopathy. J. Neurol. 2008, 255, 70-76. [CrossRef]

8. Attems, J.; Lintner, F.; Jellinger, K.A. Amyloid $\beta$ peptide 1-42 highly correlates with capillary cerebral amyloid angiopathy and Alzheimer disease pathology. Acta Neuropathol. 2004, 107, 283-291. [CrossRef]

9. Arvanitakis, Z.; Leurgans, S.E.; Wang, Z.; Wilson, R.S.; Bennett, D.A.; Schneider, J.A. Cerebral amyloid angiopathy pathology and cognitive domains in older persons. Ann. Neurol. 2011, 69, 320-327. [CrossRef]

10. Xu, W.; Xu, F.; Anderson, M.E.; Kotarba, A.; Davis, J.; Robinson, J.K.; Van Nostrand, W.E. Cerebral microvascular rather than parenchymal amyloid- $\beta$ protein pathology promotes early cognitive impairment in transgenic mice. J. Alzheimers Dis. 2013, 38, 621-632. [CrossRef]

11. Pope, S.K.; Shue, V.M.; Beck, C. Will a healthy lifestyle help prevent Alzheimer's disease? Annu. Rev. Public Health 2003, 24, 111-132. [CrossRef] [PubMed]

12. Lange-Asschenfeldt, C.; Kojda, G. Alzheimer's disease, cerebrovascular dysfunction and the benefits of exercise: From vessels to neurons. Exp. Gerontol. 2008, 43, 499-504. [CrossRef] [PubMed]

13. Cotman, C.W.; Berchtold, N.C. Exercise: A behavioral intervention to enhance brain health and plasticity. Trends Neurosci. 2002, 25, 295-301. [CrossRef]

14. Radak, Z.; Hart, N.; Sarga, L.; Koltai, E.; Atalay, M.; Ohno, H.; Boldogh, I. Exercise plays a preventive role against Alzheimer's disease. J. Alzheimers Dis. 2010, 20, 777-783. [CrossRef] [PubMed]

15. Katzman, R. Education and the prevalence of dementia and Alzheimer's disease. Neurology 1993, 43, 13-20. [CrossRef]

16. Wilson, R.S.; De Leon, C.F.M.; Barnes, L.L.; Schneider, J.A.; Bienias, J.L.; Evans, D.A.; Bennett, D.A. Participation in cognitively stimulating activities and risk of incident Alzheimer disease. JAMA 2002, 287, 742-748. [CrossRef]

17. Stern, Y.; Gurland, B.; Tatemichi, T.K.; Tang, M.X.; Wilder, D.; Mayeux, R. Influence of education and occupation on the incidence of Alzheimer's disease. JAMA 1994, 271, 1004-1010. [CrossRef]

18. Marioni, R.E.; Proust-Lima, C.; Amieva, H.; Brayne, C.; Matthews, F.E.; Dartigues, J.-F.; Jacqmin-Gadda, H. Cognitive lifestyle jointly predicts longitudinal cognitive decline and mortality risk. Eur. J. Epidemiol. 2014, 29, 211-219. [CrossRef]

19. Olson, A.K.; Eadie, B.D.; Ernst, C.; Christie, B.R. Environmental enrichment and voluntary exercise massively increase neurogenesis in the adult hippocampus via dissociable pathways. Hippocampus 2006, 16, 250-260. [CrossRef]

20. Kempermann, G.; Gast, D.; Gage, F.H. Neuroplasticity in old age: Sustained fivefold induction of hippocampal neurogenesis by long-term environmental enrichment. Ann. Neurol. 2002, 52, 135-143. [CrossRef]

21. Birch, A.M.; McGarry, N.B.; Kelly, Á.M. Short-term environmental enrichment, in the absence of exercise, improves memory, and increases NGF concentration, early neuronal survival, and synaptogenesis in the dentate gyrus in a time-dependent manner. Hippocampus 2013, 23, 437-450. [CrossRef] [PubMed] 
22. Ekstrand, J.; Hellsten, J.; Tingström, A. Environmental enrichment, exercise and corticosterone affect endothelial cell proliferation in adult rat hippocampus and prefrontal cortex. Neurosci. Lett. 2008, 442, 203-207. [CrossRef] [PubMed]

23. Ickes, B.R.; Pham, T.M.; Sanders, L.A.; Albeck, D.S.; Mohammed, A.H.; Granholm, A.-C. Long-term environmental enrichment leads to regional increases in neurotrophin levels in rat brain. Exp. Neurol. 2000, 164, 45-52. [CrossRef]

24. Rampon, C.; Jiang, C.H.; Dong, H.; Tang, Y.-P.; Lockhart, D.J.; Schultz, P.G.; Tsien, J.Z.; Hu, Y. Effects of environmental enrichment on gene expression in the brain. Proc. Natl. Acad. Sci. USA 2000, 97, 12880-12884. [CrossRef] [PubMed]

25. Ip, E.Y.-Y.; Giza, C.C.; Griesbach, G.S.; Hovda, D.A. Effects of enriched environment and fluid percussion injury on dendritic arborization within the cerebral cortex of the developing rat. J. Neurotrauma 2002, 19, 573-585. [CrossRef] [PubMed]

26. Turner, C.A.; Lewis, M.H.; King, M.A. Environmental enrichment: Effects on stereotyped behavior and dendritic morphology. Dev. Psychobiol. 2003, 43, 20-27. [CrossRef]

27. Leggio, M.G.; Mandolesi, L.; Federico, F.; Spirito, F.; Ricci, B.; Gelfo, F.; Petrosini, L. Environmental enrichment promotes improved spatial abilities and enhanced dendritic growth in the rat. Behav. Brain Res. 2005, 163, 78-90. [CrossRef]

28. Segovia, G.; Del Arco, A.; de Blas, M.; Garrido, P.; Mora, F. Effects of an enriched environment on the release of dopamine in the prefrontal cortex produced by stress and on working memory during aging in the awake rat. Behav. Brain Res. 2008, 187, 304-311. [CrossRef]

29. Benaroya-Milshtein, N.; Hollander, N.; Apter, A.; Kukulansky, T.; Raz, N.; Wilf, A.; Yaniv, I.; Pick, C. Environmental enrichment in mice decreases anxiety, attenuates stress responses and enhances natural killer cell activity. Eur. J. Neurosci. 2004, 20, 1341-1347. [CrossRef]

30. Roy, V.; Belzung, C.; Delarue, C.; Chapillon, P. Environmental enrichment in BALB/c mice: Effects in classical tests of anxiety and exposure to a predatory odor. Physiol. Behav. 2001, 74, 313-320. [CrossRef]

31. Llorens-Martin, M.; Rueda, N.; Martínez-Cué, C.; Torres-Alemán, I.; Florez, J.; Trejo, J.L. Both increases in immature dentate neuron number and decreases of immobility time in the forced swim test occurred in parallel after environmental enrichment of mice. Neuroscience 2007, 147, 631-638. [CrossRef] [PubMed]

32. Lazarov, O.; Robinson, J.; Tang, Y.-P.; Hairston, I.S.; Korade-Mirnics, Z.; Lee, V.M.-Y.; Hersh, L.B.; Sapolsky, R.M.; Mirnics, K.; Sisodia, S.S. Environmental enrichment reduces A $\beta$ levels and amyloid deposition in transgenic mice. Cell 2005, 120, 701-713. [CrossRef]

33. Hu, Y.-S.; Xu, P.; Pigino, G.; Brady, S.T.; Larson, J.; Lazarov, O. Complex environment experience rescues impaired neurogenesis, enhances synaptic plasticity, and attenuates neuropathology in familial Alzheimer's disease-linked APPswe/PS1 $\triangle E 9$ mice. FASEB J. 2010, 24, 1667-1681. [CrossRef] [PubMed]

34. Costa, D.A.; Cracchiolo, J.R.; Bachstetter, A.D.; Hughes, T.F.; Bales, K.R.; Paul, S.M.; Mervis, R.F.; Arendash, G.W.; Potter, H. Enrichment improves cognition in AD mice by amyloid-related and unrelated mechanisms. Neurobiol. Aging 2007, 28, 831-844. [CrossRef] [PubMed]

35. Arendash, G.W.; Garcia, M.F.; Costa, D.A.; Cracchiolo, J.R.; Wefes, I.M.; Potter, H. Environmental enrichment improves cognition in aged Alzheimer's transgenic mice despite stable $\beta$-amyloid deposition. Neuroreport 2004, 15, 1751-1754. [CrossRef] [PubMed]

36. Jankowsky, J.L.; Xu, G.; Fromholt, D.; Gonzales, V.; Borchelt, D.R. Environmental enrichment exacerbates amyloid plaque formation in a transgenic mouse model of Alzheimer disease. J. Neuropathol. Exp. Neurol. 2003, 62, 1220-1227. [CrossRef]

37. Jankowsky, J.L.; Melnikova, T.; Fadale, D.J.; Xu, G.M.; Slunt, H.H.; Gonzales, V.; Younkin, L.H.; Younkin, S.G.; Borchelt, D.R.; Savonenko, A.V. Environmental Enrichment Mitigates Cognitive Deficits in a Mouse Model of Alzheimer's Disease. J. Neurosci. 2005, 25, 5217-5224. [CrossRef]

38. Stern, Y. Cognitive reserve and Alzheimer disease. Alzheimer Dis. Assoc. Disord. 2006, 20, 112-117. [CrossRef]

39. Wolf, S.A.; Kronenberg, G.; Lehmann, K.; Blankenship, A.; Overall, R.; Staufenbiel, M.; Kempermann, G. Cognitive and Physical Activity Differently Modulate Disease Progression in the Amyloid Precursor Protein (APP)-23 Model of Alzheimer's Disease. Biol. Psychiatry 2006, 60, 1314-1323. [CrossRef] 
40. Cracchiolo, J.R.; Mori, T.; Nazian, S.J.; Tan, J.; Potter, H.; Arendash, G.W. Enhanced cognitive activity-Over and above social or physical activity-Is required to protect Alzheimer's mice against cognitive impairment, reduce A $\beta$ deposition, and increase synaptic immunoreactivity. Neurobiol. Learn. Mem. 2007, 88, 277-294. [CrossRef]

41. Herring, A.; Yasin, H.; Ambrée, O.; Sachser, N.; Paulus, W.; Keyvani, K. Environmental Enrichment Counteracts Alzheimer's Neurovascular Dysfunction in TgCRND8 Mice. Brain Pathol. 2008, 18, 32-39. [CrossRef] [PubMed]

42. Ambrée, O.; Leimer, U.; Herring, A.; Görtz, N.; Sachser, N.; Heneka, M.T.; Paulus, W.; Keyvani, K. Reduction of Amyloid Angiopathy and A $\beta$ Plaque Burden after Enriched Housing in TgCRND8 Mice: Involvement of Multiple Pathways. Am. J. Pathol. 2006, 169, 544-552. [CrossRef] [PubMed]

43. Herring, A.; Lewejohann, L.; Panzer, A.-L.; Donath, A.; Kröll, O.; Sachser, N.; Paulus, W.; Keyvani, K. Preventive and therapeutic types of environmental enrichment counteract beta amyloid pathology by different molecular mechanisms. Neurobiol. Dis. 2011, 42, 530-538. [CrossRef] [PubMed]

44. Anderson, M.; Xu, F.; Ou-Yang, M.H.; Davis, J.; Van Nostrand, W.E.; Robinson, J.K. Intensive 'Brain Training' Intervention Fails to Reduce Amyloid Pathologies or Cognitive Deficits in Transgenic Mouse Models of Alzheimer's Disease. J. Alzheimers Dis. 2017, 55, 1109-1121. [CrossRef]

45. Ballard, C.; Khan, Z.; Clack, H.; Corbett, A. Nonpharmacological treatment of Alzheimer disease. Can. J. Psychiatry Rev. Can. Psychiatr. 2011, 56, 589-595. [CrossRef]

46. Redick, T.S.; Shipstead, Z.; Harrison, T.L.; Hicks, K.L.; Fried, D.E.; Hambrick, D.Z.; Kane, M.J.; Engle, R.W. No evidence of intelligence improvement after working memory training: A randomized, placebo-controlled study. J. Exp. Psychol. 2013, 142, 359-379. [CrossRef]

47. Noack, H.; Lovden, M.; Schmiedek, F. On the validity and generality of transfer effects in cognitive training research. Psychol. Res. 2014, 78, 773-789. [CrossRef]

48. Shipstead, Z.; Redick, T.S.; Engle, R.W. Is working memory training effective? Psychol. Bull. 2012, 138, 628-654. [CrossRef]

49. Robison, L.S.; Popescu, D.L.; Anderson, M.E.; Francis, N.; Hatfield, J.; Sullivan, J.K.; Xu, F.; Beigelman, S.I.; Anderson, B.J.; Van Nostrand, W.E.; et al. Long-term voluntary wheel running does not alter vascular amyloid burden but reduces neuroinflammation in the Tg-SwDI mouse model of cerebral amyloid angiopathy. $J$. Neuroinflamm. 2019, 16, 144. [CrossRef]

50. Robison, L.S.; Popescu, D.L.; Anderson, M.E.; Beigelman, S.I.; Fitzgerald, S.M.; Kuzmina, A.E.; Lituma, D.A.; Subzwari, S.; Michaelos, M.; Anderson, B.J.; et al. The effects of volume versus intensity of long-term voluntary exercise on physiology and behavior in C57/Bl6 mice. Physiol. Behav. 2018, 194, 218-232. [CrossRef]

51. Witte, A.V.; Fobker, M.; Gellner, R.; Knecht, S.; Flöel, A. Caloric restriction improves memory in elderly humans. Proc. Natl. Acad. Sci. USA 2009, 106, 1255-1260. [CrossRef] [PubMed]

52. Luchsinger, J.A.; Tang, M.-X.; Shea, S.; Mayeux, R. Caloric Intake and the Risk of Alzheimer Disease. Arch. Neurol. 2002, 59, 1258-1263. [CrossRef] [PubMed]

53. Joseph, J.; Cole, G.; Head, E.; Ingram, D. Nutrition, Brain Aging, and Neurodegeneration. J. Neurosci. 2009, 29, 12795-12801. [CrossRef] [PubMed]

54. Van Cauwenberghe, C.; Vandendriessche, C.; Libert, C.; Vandenbroucke, R.E. Caloric restriction: Beneficial effects on brain aging and Alzheimer's disease. Mamm. Genome 2016, 27, 300-319. [CrossRef] [PubMed]

55. Stewart, J.; Mitchell, J.; Kalant, N. The effects of life-long food restriction on spatial memory in young and aged Fischer 344 rats measured in the eight-arm radial and the Morris water mazes. Neurobiol. Aging 1989, 10, 669-675. [CrossRef]

56. Means, L.W.; Higgins, J.L.; Fernandez, T.J. Mid-life onset of dietary restriction extends life and prolongs cognitive functioning. Physiol. Behav. 1993, 54, 503-508. [CrossRef]

57. Qin, W.; Yang, T.; Ho, L.; Zhao, Z.; Wang, J.; Chen, L.; Zhao, W.; Thiyagarajan, M.; MacGrogan, D.; Rodgers, J.T. Neuronal SIRT1 activation as a novel mechanism underlying the prevention of Alzheimer disease amyloid neuropathology by calorie restriction. J. Biol. Chem. 2006, 281, 21745-21754. [CrossRef]

58. Halagappa, V.K.; Guo, Z.; Pearson, M.; Matsuoka, Y.; Cutler, R.G.; Laferla, F.M.; Mattson, M.P. Intermittent fasting and caloric restriction ameliorate age-related behavioral deficits in the triple-transgenic mouse model of Alzheimer's disease. Neurobiol. Dis. 2007, 26, 212-220. [CrossRef]

59. Bok, E.; Jo, M.; Lee, S.; Lee, B.R.; Kim, J.; Kim, H.J. Dietary Restriction and Neuroinflammation: A Potential Mechanistic Link. Int. J. Mol. Sci. 2019, 20, 464. [CrossRef] 
60. Irizarry, M.C.; Soriano, F.; McNamara, M.; Page, K.J.; Schenk, D.; Games, D.; Hyman, B.T. A $\beta$ deposition is associated with neuropil changes, but not with overt neuronal loss in the human amyloid precursor protein V717F (PDAPP) transgenic mouse. J. Neurosci. 1997, 17, 7053-7059. [CrossRef]

61. Westerman, M.A.; Cooper-Blacketer, D.; Mariash, A.; Kotilinek, L.; Kawarabayashi, T.; Younkin, L.H.; Carlson, G.A.; Younkin, S.G.; Ashe, K.H. The relationship between A $\beta$ and memory in the Tg2576 mouse model of Alzheimer's disease. J. Neurosci. 2002, 22, 1858-1867. [CrossRef] [PubMed]

62. Bieschke, J.; Herbst, M.; Wiglenda, T.; Friedrich, R.P.; Boeddrich, A.; Schiele, F.; Kleckers, D.; del Amo, J.M.L.; Grüning, B.A.; Wang, Q. Small-molecule conversion of toxic oligomers to nontoxic $\beta$-sheet-rich amyloid fibrils. Nat. Chem. Biol. 2012, 8, 93-101. [CrossRef] [PubMed]

63. Yamamoto, K.; Tanei, Z.I.; Hashimoto, T.; Wakabayashi, T.; Okuno, H.; Naka, Y.; Yizhar, O.; Fenno, L.E.; Fukayama, M.; Bito, H.; et al. Chronic optogenetic activation augments abeta pathology in a mouse model of Alzheimer disease. Cell Rep. 2015, 11, 859-865. [CrossRef] [PubMed]

64. Kamenetz, F.; Tomita, T.; Hsieh, H.; Seabrook, G.; Borchelt, D.; Iwatsubo, T.; Sisodia, S.; Malinow, R. APP processing and synaptic function. Neuron 2003, 37, 925-937. [CrossRef]

65. Nilsson, M.; Perfilieva, E.; Johansson, U.; Orwar, O.; Eriksson, P.S. Enriched environment increases neurogenesis in the adult rat dentate gyrus and improves spatial memory. J. Neurobiol. 1999, 39, 569-578. [CrossRef]

66. Xu, H.; Gelyana, E.; Rajsombath, M.; Yang, T.; Li, S.; Selkoe, D. Environmental enrichment potently prevents microglia-mediated neuroinflammation by human amyloid $\beta$-protein oligomers. J. Neurosci. 2016, 36, 9041-9056. [CrossRef]

67. Beauquis, J.; Pavía, P.; Pomilio, C.; Vinuesa, A.; Podlutskaya, N.; Galvan, V.; Saravia, F. Environmental enrichment prevents astroglial pathological changes in the hippocampus of APP transgenic mice, model of Alzheimer's disease. Exp. Neurol. 2013, 239, 28-37. [CrossRef]

68. Ngandu, T.; Lehtisalo, J.; Solomon, A.; Levalahti, E.; Ahtiluoto, S.; Antikainen, R.; Backman, L.; Hanninen, T.; Jula, A.; Laatikainen, T.; et al. A 2 year multidomain intervention of diet, exercise, cognitive training, and vascular risk monitoring versus control to prevent cognitive decline in at-risk elderly people (FINGER): A randomised controlled trial. Lancet 2015, 385, 2255-2263. [CrossRef]

69. Dhana, K.; Evans, D.A.; Rajan, K.B.; Bennett, D.A.; Morris, M.C. Impact of healthy lifestyle factors on the risk of Alzheimer's dementia: Findings from two prospective cohort studies. Alzheimers Dement. 2019, 15, P207. [CrossRef]

70. Kuzma, E.; Lourida, I.; Hannon, E.; Littlejohns, T.J.; Langa, K.M.; Hyppönen, E.; Llewellyn, D.J. Genetic risk, lifestyle, and dementia. Alzheimers Dement. 2019, 15, P890. [CrossRef]

71. Davis, J.; Xu, F.; Miao, J.; Previti, M.L.; Romanov, G.; Ziegler, K.; Van Nostrand, W.E. Deficient cerebral clearance of vasculotropic mutant Dutch/Iowa Double Aß in human AßPP transgenic mice. Neurobiol. Aging 2006, 27, 946-954. [CrossRef] [PubMed]

72. Davis, J.; Xu, F.; Deane, R.; Romanov, G.; Previti, M.L.; Zeigler, K.; Zlokovic, B.V.; Van Nostrand, W.E. Early-onset and robust cerebral microvascular accumulation of amyloid $\beta$-protein in transgenic mice expressing low levels of a vasculotropic Dutch/Iowa mutant form of amyloid $\beta$-protein precursor. J. Biol. Chem. 2004, 279, 20296-20306. [CrossRef] [PubMed]

73. Miao, J.; Xu, F.; Davis, J.; Otte-Höller, I.; Verbeek, M.M.; Van Nostrand, W.E. Cerebral microvascular amyloid $\beta$ protein deposition induces vascular degeneration and neuroinflammation in transgenic mice expressing human vasculotropic mutant amyloid $\beta$ precursor protein. Am. J. Pathol. 2005, 167, 505-515. [CrossRef]

74. Xu, F.; Grande, A.M.; Robinson, J.K.; Previti, M.L.; Vasek, M.; Davis, J.; Van Nostrand, W.E. Early-Onset Subicular Microvascular Amyloid and Neuroinflammation Correlate With Behavioral Deficits in Vasculotropic Mutant APP Transgenic Mice. Neuroscience 2007, 146, 98-107. [CrossRef] [PubMed]

75. Prut, L.; Belzung, C. The open field as a paradigm to measure the effects of drugs on anxiety-like behaviors: A review. Eur. J. Pharm. 2003, 463, 3-33. [CrossRef]

76. Deacon, R.M.J. Digging and marble burying in mice: Simple methods for in vivo identification of biological impacts. Nat. Protoc. 2006, 1, 122-124. [CrossRef]

(C) 2020 by the authors. Licensee MDPI, Basel, Switzerland. This article is an open access article distributed under the terms and conditions of the Creative Commons Attribution (CC BY) license (http://creativecommons.org/licenses/by/4.0/). 